\section{Check for updates}

Cite this: J. Mater. Chem. A, 2018, 6, 11362

\title{
The critical role of hydrogen on the stability of oxy- hydroxyl defect clusters in uranium oxide $\uparrow$
}

\begin{abstract}
Joseph M. Flitcroft, (D) a Marco Molinari, (D) *ab Nicholas A. Brincat, ${ }^{c}$ Nicholas R. Williams, ${ }^{c}$ Mark T. Storr, ${ }^{c}$ Geoffrey C. Allen ${ }^{\text {d }}$ and Stephen C. Parker (iD *a

Despite considerable work applying ab initio techniques to model the role of defects on mechanical, structural and electronic properties of oxides, there has been little on the role of trapped hydrogen, despite it being virtually always present. We propose a framework for identifying reversible and irreversible hydrogen traps. We demonstrate that the thermodynamic stability of oxy-hydroxyl defects is defined by an interplay of formation and binding energies. This framework is applicable to all oxides and is essential for describing the solubility and diffusivity of hydrogen at the macroscopic level. For the most important actinide oxide in nuclear energy, uranium oxide, hydrogen significantly impacts the stability of oxygen defect clusters, and with increased local hydrogen concentration it forms irreversible traps. Crucially, hydrogen stabilises isolated Willis clusters, named after their discoverer and originally reported in 1963, which all subsequent ab initio calculations have predicted to be unstable, but of course, none considered hydrogen.
\end{abstract}

Received 27th March 2018

Accepted 21st May 2018

DOI: $10.1039 / \mathrm{c} 8 \mathrm{ta0} 2817 f$

rsc.li/materials-a

hydride, trapping of hydrogen within the oxide coating layer is

\section{Introduction}

The presence of hydrogen in oxide materials is often overlooked despite its significant impact on materials properties, ${ }^{1-4}$ including mechanical resistivity, ${ }^{5}$ conductivity, ${ }^{6}$ (photo-)catalysis, ${ }^{7-9}$ gate materials, ${ }^{10}$ insulator to metal transition ${ }^{11}$ and chemo- and photo-chromism. ${ }^{12}$ Perhaps one of the most compelling arguments, for investigating hydrogen defects, is that control over these materials properties would only be gained when a complete survey of the chemistry and atom-level structures of complex defects is compiled.

Hydrogen is of primary concern in metals and uranium is no exception, with its legacy from the first generation of nuclear reactors. As a metal, uranium is susceptible to oxidation in the presence of water vapour and oxygen forming a thin uranium oxide coating layer that provides a protective physical barrier that quenches corrosion of the metal. In common with other metals, ${ }^{5}$ the aqueous corrosion of uranium generates hydrogen species that permeate through the oxide layer ${ }^{13-15}$ and react with the metal to form hydride species. ${ }^{16}$ However, uranium hydride is pyrophoric and thus it is a major concern in the design of long-term storage facilities. To prevent formation of the

a Department of Chemistry, University of Bath, Bath, BA2 7AY, UK. E-mail: s.c.parker@ bath.ac.uk

${ }^{b}$ Department of Chemistry, University of Huddersfield, Queensgate, Huddersfield, HD1 3DH, UK. E-mail: m.molinari@hud.ac.uk

${ }^{c} A W E$ plc, Aldermaston, Reading, Berkshire, RG7 4PR, UK

${ }^{d}$ Interface Analysis Centre, University of Bristol, Bristol, BS2 8BS, UK

$\dagger$ Electronic supplementary information (ESI) available. See DOI: $10.1039 / \mathrm{c} 8 \mathrm{ta} 02817 \mathrm{f}$ required, and this can be best achieved by identifying and controlling the defects that efficiently trap hydrogen.

In the case of uranium oxide, experimental data on solubility and diffusivity of hydrogen is limited, ${ }^{17-19}$ and the nature of the diffusing hydrogen species is still undetermined, with both molecular ${ }^{17}$ and atomic ${ }^{18,19}$ hydrogen proposed. The latter, in particular, is essential for predicting any diffusivity and trapping. Evidence of hydrogen trapping was first reported by Sherman and Olander, ${ }^{19}$ who saw the release of hydrogen from samples at high temperatures $\left(800-1450{ }^{\circ} \mathrm{C}\right)$. Wheeler suggested that this hydrogen may be in the form of strongly bound species (i.e. hydroxyl groups) that are effectively trapped. ${ }^{17}$

There is also evidence that oxygen deficiency increases hydrogen solubility compared to oxygen-rich conditions. ${ }^{19}$ In the latter, the excess oxygen is incorporated as isolated oxygen interstitials at low oxygen partial pressure, which cluster at higher oxygen concentration..$^{20-28}$ This leads to a variety of potential hydrogen traps. A further level of complexity is then due to the microstructure of polycrystalline oxide materials, which has an impact on the diffusivity of hydrogen, ${ }^{17-19}$ as it does for the diffusivity of oxygen in fluorite oxides. ${ }^{29-32}$

Glascott proposed a comprehensive mathematical model for hydriding initiation in uranium metal, which included hydrogen diffusivity in the oxide coating layer. ${ }^{33,34}$ However, such macroscopic modelling is unable to provide insight into the structural features that interact directly with hydrogen in the material. This can only be realised through atomistic modelling that can identify the geometry of hydrogen trapping sites. 
Recently, $a b$ initio studies have begun to characterise the nature of hydrogen species, and have found that both hydroxyl groups and hydride species may form, with the latter identified as more favourable. ${ }^{35,36}$ Other theoretical work has focussed on the adsorption, desorption and dissociation of water on uranium oxide surfaces, ${ }^{37,38}$ which is one of the routes that hydrogen can be incorporated into the uranium oxide lattice and before reaching the metal. Whereas there is data suggesting the existence of hydrogen traps in oxygen-rich uranium oxide, there are no atom-level models to support this proposition. The present work applies ab initio modelling techniques to examine the dependence of hydrogen trapping on oxygen defect clusters under oxygen-rich conditions.

\section{Methodology}

\section{First principle calculations}

A cubic unit cell comprised of $32 \mathrm{UO}_{2}$ units was generated by a 2 $\times 2 \times 2$ expansion of the fluorite $4 \mathrm{UO}_{2}$ unit cell. All calculations were performed using the VASP $\operatorname{code}^{39}{ }^{39}$ with PAW pseudopotentials and the GGA PBE functional. ${ }^{\mathbf{4 0}}$ The Dudarev ${ }^{\mathbf{4 1}}$ approach was used for the implementation of the onsite Hubbard $\mathrm{U}$ parameter, with $U=4.5 \mathrm{eV}$ and $J=0.54 \mathrm{eV} .^{42}$ The planewave cut-off energy was set at $400 \mathrm{eV}$ and a $\Gamma$-centred $2 \times 2 \times 2$ Monkhorst-Pack $k$-point grid was used for all calculations, in line with previous work ${ }^{22,25,43}$ and convergence criteria for the electronic and ionic relaxations were $1 \times 10^{-6} \mathrm{eV}$ per atom and $1 \times 10^{-2} \mathrm{eV} \mathrm{A}^{-1}$, respectively. All calculations were performed at constant pressure with collinear $1 \mathrm{k}$ antiferromagnetic ordering. This is considered an appropriate approximation for the experimentally observed $3 \mathrm{k}$ non-collinear antiferromagnetic ordering, ${ }^{29,44}$ and is line with previous work. ${ }^{22,25,26,28}$ VASP accounts for relativistic effects through scalar relativistic methods ${ }^{45,46}$ and spin orbit coupling (SOC). In our previous work, ${ }^{35}$ we examined the effect of SOC on hydrogen defects in $\mathrm{UO}_{2}$. The produced a consistent shift in the energies, which is in line with previous work for $\mathrm{UO}_{2}{ }^{47,48}$ SOC does not remove the tetragonal distortion caused by the antiferromagnetic ordering, which can only be removed using the experimentally observed 3k non-collinear ordering. ${ }^{44}$ The effect of SOC has also been shown to be negligible on structure, relative stability and electronic properties of other actinide oxides. ${ }^{49}$ For all these reasons and as the inclusion of SOC vastly increases the computational expense, it has not been included in here. All structural models were generated using the METADISE ${ }^{50}$ code and all structural figures were created using VESTA. ${ }^{51}$

\section{Results and discussion}

\section{$\mathrm{UO}_{2+x}$ structural models}

The two smallest oxygen clusters proposed in uranium oxide are the split di-interstitial $\left(I_{2}{ }^{x}\right)$ and the $2: 2: 2$ Willis cluster $\left(\mathrm{W}_{222}\right)$, shown in Fig. 1. We use the nomenclature common in the literature for the split interstitial clusters $\left(I_{2}{ }^{x}\right)^{22}$ and have adapted this to also refer to the Willis clusters $\left(\mathrm{W}_{222}\right)$. Upon the incorporation of excess oxygen the $\mathrm{UO}_{2}$ lattice is oxidised, such that for every additional oxygen, two uranium atoms are

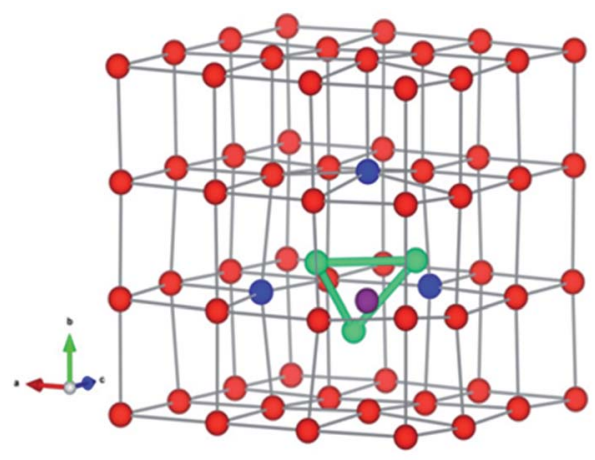

a Split di-interstitial cluster, $I_{2}^{x}$

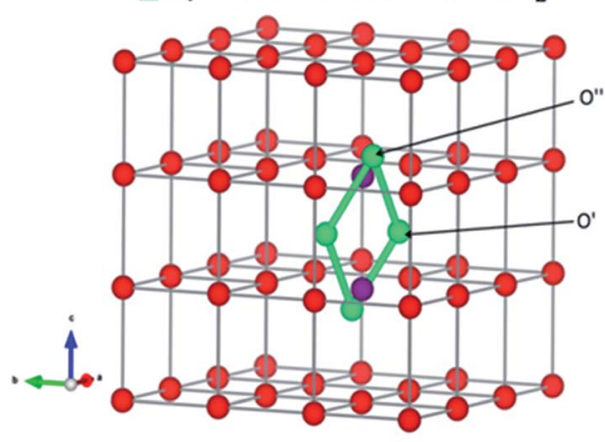

b $2: 2: 2$ Willis cluster, $W_{222}$

Fig. 1 Structure of oxygen defect clusters in $\cup_{2}$. (a) Split di-interstitial $\left(/_{2}{ }^{x}\right)$ and $(b) 2: 2: 2$ Willis $\left(W_{222}\right)$ clusters. Lattice oxygen shown in red. $\mathrm{U}^{4+} / \mathrm{U}^{5+}$ are not shown for clarity. Oxygen interstitial $\left(\mathrm{O}_{\mathrm{i}}^{\prime \prime}\right)$ shown in green. Significantly (>10\%) displaced lattice oxygen shown in dark blue. Oxygen vacancies $\left(V_{O}^{*}\right)$ shown in purple. Bonds have been drawn in green to highlight defect cluster geometries.

oxidised from $\mathrm{U}^{4+}$ to $\mathrm{U}^{5+}$. The Kroger-Vink notation is commonly used in the literature for defects in solids ${ }^{22,26}$ and we use this to describe the point defects used as reference states.

A $I_{2}{ }^{x}$ cluster (Fig. 1a) has a central oxygen vacancy $\left(V_{\mathrm{O}}^{* *}\right)$ surrounded by three oxygen interstitials $\left(\mathrm{O}_{\mathrm{i}}^{\prime \prime}\right)$ located approximately $1.6 \AA$ away in $\langle 111\rangle$ directions. This causes the displacement of three lattice oxygen by approximately $0.3 \AA$ from their lattice sites, highlighted in blue in Fig. 1a. In the models presented here the excess oxygen changes the stoichiometry from $\mathrm{UO}_{2.00}$ to $\mathrm{UO}_{2.06}$, and leads to the oxidation of four nearest neighbour uranium ions to the cluster from $\mathrm{U}^{4+}$ to $\mathrm{U}^{5+}$. A $I_{2}{ }^{x}$ cluster is found to have a formation energy of $-123 \mathrm{~kJ} \mathrm{~mol}^{-1}$ in agreement with previously reported literature values. ${ }^{22,23}$

A $\mathrm{W}_{222}$ (Fig. 1b) consists of two $V_{\mathrm{O}}^{*}$ and four $\mathrm{O}_{\mathrm{i}}^{\prime \prime}$ each located approximately $1 \AA$ from an octahedral interstitial site; two $\mathrm{O}_{\mathrm{i}}^{\prime \prime}$ are found in $\langle 110\rangle$ directions $\left(\mathrm{O}^{\prime}\right)$ and two in $\langle 111\rangle$ directions $\left(\mathrm{O}^{\prime \prime}\right)$. The $\mathrm{W}_{222}$ cluster was the first defect cluster proposed to rationalise the $\mathrm{UO}_{2+x}$ structure, ${ }^{20}$ and was initially predicted to be stable using interatomic potential model calculations. ${ }^{21}$ However, the advent of DFT has demonstrated single, isolated $\mathrm{W}_{222}$ clusters are unstable with respect to $I_{2}{ }^{x}$ clusters. $^{23}$ Recently, DFT calculations have found that edge-sharing $\mathrm{W}_{222}$ clusters are stable in $\mathrm{UO}_{2+x}$, but only in a narrow composition range $(0.125<x<0.25),{ }^{25}$ becoming unstable by $x=0.33,{ }^{26}$ 
emphasising how sensitive $\mathrm{UO}_{2}$ defect chemistry is to oxygen partial pressure.

\section{$\mathrm{UO}_{2+x} \mathrm{H}_{y}$ structural models}

Hydrogen was added to the $\mathrm{UO}_{2.06}$ models of $\mathrm{W}_{222}$ (Willis cluster, Fig. 1b) and $I_{2}{ }^{x}$ (split di-interstitial cluster, Fig. 1a) clusters and the local hydrogen concentration was varied from 117 to $467 \mu \mathrm{g} \mathrm{H} / \mathrm{g} \mathrm{UO}_{2}$, which is equivalent to $y$ in $\mathrm{UO}_{2+x} \mathrm{H}_{y}$ varying from around 0.03 to 0.12 . This is achieved by the addition of 1 to 4 hydrogen species to the oxygen clusters in simulation cell of $\mathrm{U}_{32} \mathrm{O}_{62+2}$. The addition of hydrogen to the oxygen clusters resulted in the formation of hydroxyl species within the cluster. As the defect clusters are made of oxygen and hydroxyl species these defect clusters will now collectively be referred to as oxy-hydroxyl clusters. The chosen configurations were selected to maximise the interactions between the oxygen and hydrogen species; details in the ESI. $\uparrow$ The formation of each hydroxyl group within the oxygen defect split di-interstitial and Willis clusters (each containing $4 \mathrm{U}^{5+}$ ) results in the reduction of a $\mathrm{U}^{5+}$ to $\mathrm{U}^{4+}$. The concentration of $\mathrm{U}^{5+}$ in each oxy-hydroxyl cluster is reported in ESI. $\dagger$

It is important to note that, hydrogen can interact with oxygen clusters in different ways, and as we discuss later this drastically impacts the stability of the oxy-hydroxyl cluster. The newly formed hydroxyl group can hydrogen bond to lattice oxygen ions $(L)$ or defect oxygen ions belonging to the cluster $(D)$. This makes only two different conformations for each local hydrogen concentration in a $I_{2}{ }^{x}\left({ }^{L} I_{2}{ }^{x}\right.$ and $\left.{ }^{D} I_{2}{ }^{x}\right)$, as it is composed of three equivalent $\mathrm{O}_{\mathrm{i}}^{\prime \prime}$ (Fig. 1a). The lower symmetry of the Willis cluster (arising from the two symmetrically inequivalent $\mathrm{O}_{\mathrm{i}}^{\prime \prime}$ ) is responsible for the greater number of possible distinct configurations; e.g. ${ }^{D} \mathrm{~W}_{222}^{\mathrm{O}^{\prime}, 2 \mathrm{O}^{\prime \prime}}$ denotes three hydrogen atoms, one at a $\mathrm{O}^{\prime}$ interstitial site and one at each of the two $\mathrm{O}^{\prime \prime}$ sites, and all three species are hydrogen bonded oxygen species of the defect cluster $(D)$.

\section{Energetics of hydrogen in $\mathrm{UO}_{2+x}$}

In order to define irreversible and reversible hydrogen traps it is necessary to introduce two energy terms, the formation and the binding energies of oxy-hydroxyl clusters.

The formation of the oxy-hydroxyl clusters is considered as the energy of dissolving hydrogen and oxygen gas into a $\mathbf{U O}_{2}$ matrix according to eqn (1).

$$
\mathrm{UO}_{2.00}+0.03 \mathrm{O}_{2}+\frac{y}{2} \mathrm{H}_{2} \rightarrow \mathrm{UO}_{2.06} \mathrm{H}_{y}
$$

with $y$ taking values of $0.03,0.06,0.09$ or 0.12 , corresponding to $117,234,351$ or $468 \mu \mathrm{g} \mathrm{H} / \mathrm{g} \mathrm{UO}_{2}$, respectively. The thermodynamic stability of oxy-hydroxyl clusters is expressed using the formation energy ( $\left.E_{\text {Form }}\right)$ of an oxy-hydroxyl defect cluster, normalised for the hydrogen concentration,

$$
E_{\mathrm{Form}}=\frac{E_{\mathrm{UO}_{2.06} \mathrm{H}_{y}}-\left(E_{\mathrm{UO}_{2.00}}+\frac{y}{2} E_{\mathrm{H}_{2}}+0.03 E_{\mathrm{O}_{2}}\right)}{y}
$$

where $E_{\mathrm{UO}_{2.00}}$ and $E_{\mathrm{UO}_{2.06} \mathrm{H}_{y}}$ are the energies of stoichiometric $\mathrm{UO}_{2.00}$ and hydrogen doped oxygen-rich $\mathrm{UO}_{2.06}, E_{\mathrm{H}_{2}}$ and $E_{\mathrm{O}_{2}}$ are the energies of molecular $\mathrm{H}_{2}$ and $\mathrm{O}_{2}$, respectively. A negative value of formation energy indicates that the oxy-hydroxyl cluster is stable.

In order to assess whether the oxy-hydroxyl clusters are more energetically favourable than isolated point defects, eqn (3) is considered, where the most stable isolated hydrogen defect is $\left[\mathrm{U}_{\mathrm{U}}^{\cdot}+\mathrm{H}_{\mathrm{i}}^{\prime}\right]$ comprising of a hole on the uranium as $\mathrm{U}^{5+}\left(\mathrm{U}_{\mathrm{U}}^{*}\right)$ compensating the hydride ion $\left(\mathrm{H}_{\mathrm{i}}^{\prime}\right)$. The charge state of the hydrogen interstitial is dependent on the location in the lattice (Fig. 2), where the hydride is more stable than the protonic form by $26 \mathrm{~kJ} \mathrm{~mol}^{-1}$. The isolated oxygen interstitial compensated by two $\mathrm{U}^{5+}$ is given by $\left[2 \mathrm{U}_{\mathrm{U}}^{*}+\mathrm{O}_{\mathrm{i}}^{\prime \prime}\right]$. These interstitial defects come together to form the oxy-hydroxyl defect cluster [cluster], either based on the split di-interstitial, $I_{2}{ }^{\mathrm{x}}$, $\left[(4-n) U_{\mathrm{U}}^{*}+3 \mathrm{O}_{\mathrm{i}}^{\prime \prime}+V_{\mathrm{O}}^{*}+n \mathrm{H}_{\mathrm{i}}^{*}\right]$ or the $2: 2: 2$ Willis cluster, $\mathrm{W}_{222}, \quad\left[(4-n) \mathrm{U}_{\mathrm{U}}^{\cdot}+4 \mathrm{O}_{\mathrm{i}}^{\prime \prime}+2 V_{\mathrm{O}}^{*}+n \mathrm{H}_{\mathrm{i}}^{*}\right], \quad$ in the presence of hydrogen. In every case, hydrogen now forms protonic defects and so reduces the $\mathrm{U}^{5+}$ associated with the hydride to $\mathrm{U}^{4+}$ and reduces an additional $\mathrm{U}^{5+}$ associated with the $\mathrm{O}_{\mathrm{i}}^{\prime \prime}$, leading to the formation of the cluster in a simulation cell with a stoichiometry of $\mathrm{UO}_{2.06} \mathrm{H}_{y}$.

$$
2\left[2 \mathrm{U}_{\mathrm{U}}^{\cdot}+\mathrm{O}_{\mathrm{i}}^{\prime \prime}\right]+n\left[\mathrm{U}_{\mathrm{U}}^{\cdot}+\mathrm{H}_{\mathrm{i}}^{\prime}\right] \stackrel{\mathrm{UO}_{2.00}}{\longrightarrow}[\text { cluster }]+2 n \mathrm{U}_{\mathrm{U}}^{\mathrm{x}}
$$

The preference for formation of oxy-hydroxyl clusters over isolated point defects (i.e. separated oxygen interstitial $\mathrm{O}_{\mathrm{i}}^{\prime \prime}$ and hydride) is expressed using the binding energy ( $\left.E_{\text {Bind }}\right)$ of the oxyhydroxyl cluster per hydrogen atom in the simulation cell, $n$,

$$
E_{\text {Bind }}=\frac{E_{[\text {cluster }]}-\left(n E_{\left[\mathrm{U}_{\mathrm{U}}^{*}+\mathrm{H}_{\mathrm{i}}^{\prime}\right]}+2 E_{\left[2 \mathrm{U}_{\mathrm{U}}^{*}+\mathrm{O}_{\mathrm{i}}^{\prime \prime}\right]}\right)}{n}
$$

where each of the defect energies are defined as the difference in energy between the defective cell and the equivalent stoichiometric cell containing the same number of $\mathrm{UO}_{2}$ formula

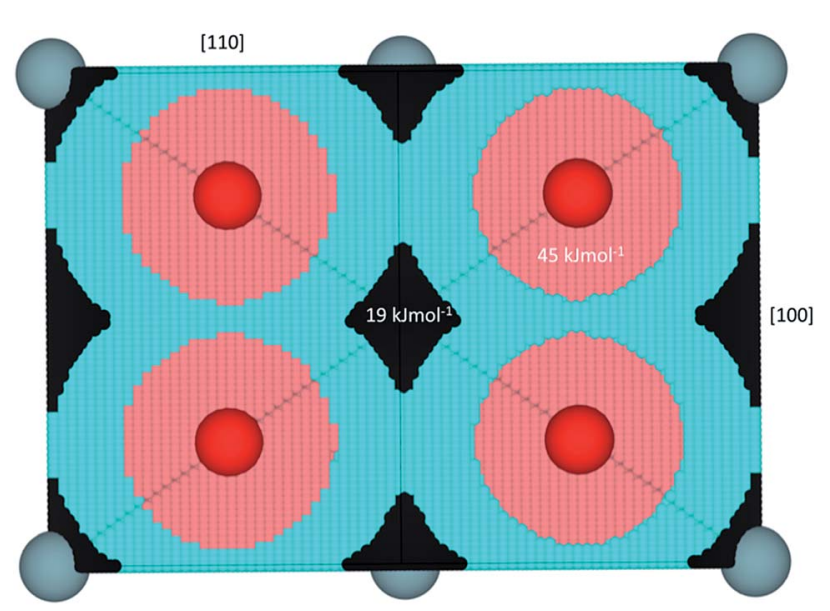

Fig. 2 Representation of hydrogen behavior in $\mathrm{UO}_{2}$ projected in a [110] direction. Black represents regions where hydride is predicted to be energetically most stable, light blue the $\mathrm{H}^{*}$ radical, pink protonic behavior (i.e. forms a hydroxyl), red the lattice oxygen and blue are the uranium ions. The energies of formation for a hydride or hydroxyl defect by dissolving $\mathrm{H}_{2}$ gas into $\mathrm{UO}_{2}$ are shown on the respective regions. Values taken from ref. 35. 
units, e.g. $E_{\text {cluster }}=E_{\mathrm{UO}_{2.06} \mathrm{H}_{y}}-E_{\mathrm{UO}_{2}}$. The most stable isolated interstitial species within $\mathrm{UO}_{2}$ for hydrogen (i.e. the hydride anion) and oxygen (i.e. an interstitial oxygen). For an isolated hydrogen $\left(E_{\mathrm{H}_{\mathrm{i}}^{\prime}}\right)$ this is a hydride $\left(E_{\mathrm{Form}}=19 \mathrm{~kJ} \mathrm{~mol}^{-1}\right),{ }^{35}$ and an $\mathrm{O}_{\mathrm{i}}^{\prime \prime}$ in stoichiometric $\mathrm{UO}_{2}\left(E_{\mathrm{O}_{\mathrm{i}}^{\prime \prime}}\right)$ for oxygen, with a formation energy calculated to be $-119 \mathrm{~kJ} \mathrm{~mol}^{-1}$ in agreement with previous literature. ${ }^{27}$ The reference energy for uranium oxide is the energy of stoichiometric $\mathrm{UO}_{2}$. A negative value of binding energy indicates an energetic preference for the interstitial species to cluster in an oxy-hydroxyl defect cluster rather than form isolated point defects within the $\mathrm{UO}_{2}$ lattice, i.e. hydride and $\mathrm{O}_{\mathrm{i}}^{\prime \prime}$. We follow the procedure of Minervini et al. ${ }^{52}$ for calculating the binding energy.

\section{The most stable oxy-hydroxyl $\mathrm{UO}_{2+x} \mathrm{H}_{y}$ clusters}

The structures of the most stable configurations at each local hydrogen clusters at each local hydrogen concentration, 117 to $467 \mu \mathrm{g} / \mathrm{g} \mathrm{UO}_{2}$, are presented in Fig. 3 along with their formation and binding energies. Data for all other configurations along with their energetics is presented in the ESI. $\dagger$ The most stable cluster is based on a $I_{2}{ }^{x}$ (split di-interstitial) geometry at local concentrations of 117 and $351 \mu \mathrm{g} \mathrm{H} / \mathrm{g} \mathrm{UO}_{2}$, which correspond to 1 and 3 hydrogen species added to the oxygen cluster $\left(-146\right.$ and $\left.-95 \mathrm{~kJ} \mathrm{~mol}^{-1 / \mathrm{H}}\right)$. This results in the reduction of $1 \mathrm{U}^{5+}$ to $1 \mathrm{U}^{4+}$ and $3 \mathrm{U}^{5+}$ to $3 \mathrm{U}^{4+}$ within the $\mathrm{UO}_{2}$ lattice respectively, as the oxidised $\mathrm{UO}_{2+x}$ including a split diinterstitial cluster contains $4 \mathrm{U}^{5+}$. Whereas the most stable $\mathrm{W}_{222}$ (Willis) cluster is found at local concentrations of $234 \mu \mathrm{g}$ $\mathrm{H} / \mathrm{g} \mathrm{UO}_{2}$ and $467 \mu \mathrm{g} \mathrm{H} / \mathrm{g} \mathrm{UO}_{2}$, which correspond to 2 and 4 hydrogen species added to the oxygen cluster $(-119$ and $\left.-76 \mathrm{~kJ} \mathrm{~mol}^{-1} / \mathrm{H}\right)$, this is balanced by the reduction of $2 \mathrm{U}^{5+}$ at $234 \mu \mathrm{g} \mathrm{H} / \mathrm{g} \mathrm{\textrm {UO } _ { 2 }}$ and complete reduction of all $\mathrm{U}^{5+}$ at $467 \mu \mathrm{g} \mathrm{H} / \mathrm{g}$ $\mathrm{UO}_{2}$. In these clusters there is a strong interaction between the hydroxyl groups and lattice oxygen atoms. There seems to be an odd-even relationship for the most stable oxy-hydroxyl clusters. Oxygen clusters with odd numbers of interstitials oxygen atoms, the $I_{2}{ }^{x}$, are stabilized by an odd number of hydrogen species, whereas oxygen clusters with even numbers of oxygen interstitials $\left(\mathrm{W}_{222}\right)$ are stabilized by an even number of hydrogen species.

\section{Energetics of oxy-hydroxyl $\mathrm{UO}_{2+x} \mathrm{H}_{y}$ clusters as a function of cluster geometry}

Fig. 4 shows the formation (eqn (2)) and binding (eqn (4)) energies (in $\mathrm{kJ} \mathrm{mol}^{-1}$ ) per hydrogen species as a function of local hydrogen concentration $\left([\mathrm{H}]\right.$ in $\left.\mu \mathrm{g} \mathrm{H} / \mathrm{g} \mathrm{UO}_{2}\right)$ for the most stable configurations of the oxy-hydroxyl clusters. We provide separate figures depending on the nature of the oxygen cluster either split di-interstitial $\left(I_{2}{ }^{x}\right)$ or Willis $\left(\mathrm{W}_{222}\right)$ clusters, and whether the newly formed hydroxyl group hydrogen bonds to lattice oxygen ions $(L)$ or defect oxygen ions belonging to the cluster $(D)$. This gives four different combinations ${ }^{L} I_{2}{ }^{x},{ }^{D} I_{2}{ }^{x},{ }^{L} \mathrm{~W}_{222}$ and ${ }^{D} \mathrm{~W}_{222}$. In each case addition of hydrogen to the oxygen defect cluster resulted in favourable formation energies, however these become less favourable with increasing hydrogen concentration and the effect is less pronounced for ${ }^{D} \mathrm{~W}_{222}$ (Fig. 4d). Additionally, oxy-hydroxyl clusters where a hydrogen bonding network is formed with lattice oxygen atoms (Fig. 4a and c) are always favoured compared to those with a hydrogen bonding network formed within the oxygen of the defect cluster (Fig. 4b and 3d). This shows a preference for the hydroxyl groups in the cluster to be arranged such that they hydrogen bond with oxygen of the lattice $(L)$ rather than oxygen of the defect $(D)$.

The preference for defect clusters over isolated point defects is expressed by the binding energy. This is generally unfavourable (i.e. isolated point defects dominate) at low hydrogen concentrations (117-234 $\mu \mathrm{g} \mathrm{H} / \mathrm{g} \mathrm{UO}_{2}$ ) and becomes increasingly favourable (i.e. defect clusters dominate) at higher concentrations (351-467 $\mu \mathrm{g} \mathrm{H} / \mathrm{g} \mathrm{UO}_{2}$ ). At the highest concentration (467 $\mu \mathrm{g} \mathrm{H} / \mathrm{g} \mathrm{UO}_{2}$ ) all clusters with favourable formation energies also have favourable binding energies (Fig. 4). There is no straightforward correlation between stability of the clusters and the total number of hydrogen bonds (Fig. 4). It appears that as the hydrogen concentration increases the number of hydrogen bonds per hydrogen decreases with the exception of ${ }^{L} \mathrm{~W}_{222}$ clusters (Fig. 4c).

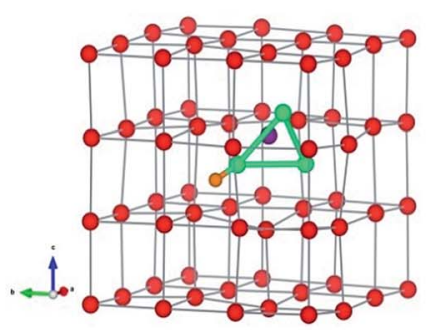

$$
\begin{gathered}
\text { a Split di-interstitial, }{ }^{{ }^{L} I_{2}^{x}} \\
\mathrm{E}_{\text {Form }}=-147 \mathrm{kJmol}^{-1} \\
\mathrm{E}_{\text {Bind }}=69 \mathrm{kJmol}^{-1}
\end{gathered}
$$

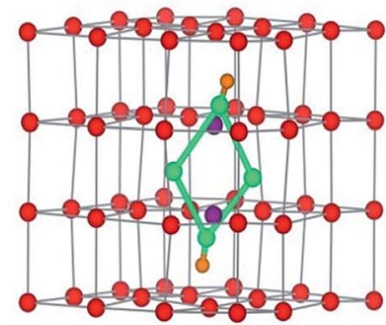

$$
\begin{gathered}
\text { b 2:2:2 Willis cluster, }{ }^{L} W_{222}^{2 O^{\prime}} \\
\mathrm{E}_{\text {Form }}=-119 \mathrm{kJmol}^{-1} \\
\mathrm{E}_{\text {Bind }}=-20 \mathrm{kJmol}^{-1}
\end{gathered}
$$

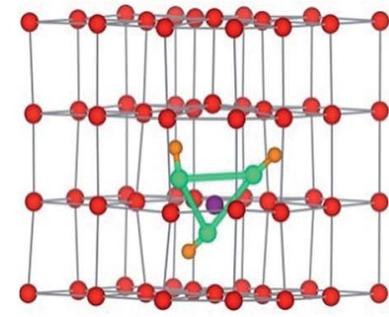

$$
\begin{gathered}
\text { c Split di-interstitial, }{ }^{L}{ }_{1} T_{2}^{x} \\
\mathrm{E}_{\text {Form }}=-94 \mathrm{kJmol}^{-1} \\
\mathrm{E}_{\text {Bind }}=-35 \mathrm{kJmol}^{-1}
\end{gathered}
$$

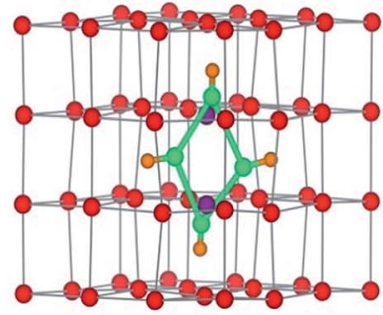

$$
\begin{gathered}
\text { d 2:2:2 Willis cluster, }{ }^{L} W_{222}^{2 O^{\prime}, 20^{\prime \prime}} \\
\mathrm{E}_{\text {Form }}=-76 \mathrm{kJmol}^{-1} \\
\mathrm{E}_{\text {Bind }}=-38 \mathrm{kJmol}^{-1}
\end{gathered}
$$

Fig. 3 Structure of oxy-hydroxyl defect clusters in $\cup_{2}$. Most stable defect clusters at (a) $117 \mu \mathrm{g} \mathrm{H} / \mathrm{g} \mathrm{UO} 2$ (b) $234 \mu \mathrm{g} \mathrm{H} / \mathrm{g} \cup \mathrm{O}_{2}$ (c) $351 \mu \mathrm{g} \mathrm{H} / \mathrm{g} \mathrm{UO} 2$ (d) $468 \mu \mathrm{g} \mathrm{H} / \mathrm{g} \mathrm{UO} 2$ local hydrogen concentration. Lattice oxygen shown in red. $U^{4+} / \mathrm{U}^{5+}$ not shown for clarity. Oxygen interstitial $\left(\mathrm{O}_{i}^{\prime \prime}\right)$ shown in green. Oxygen vacancies $\left(V_{O}^{*}\right)$ shown in purple. Hydrogen shown in orange. Bonds have been drawn in green to highlight defect cluster geometries. Formation and binding energies are given per hydrogen. 


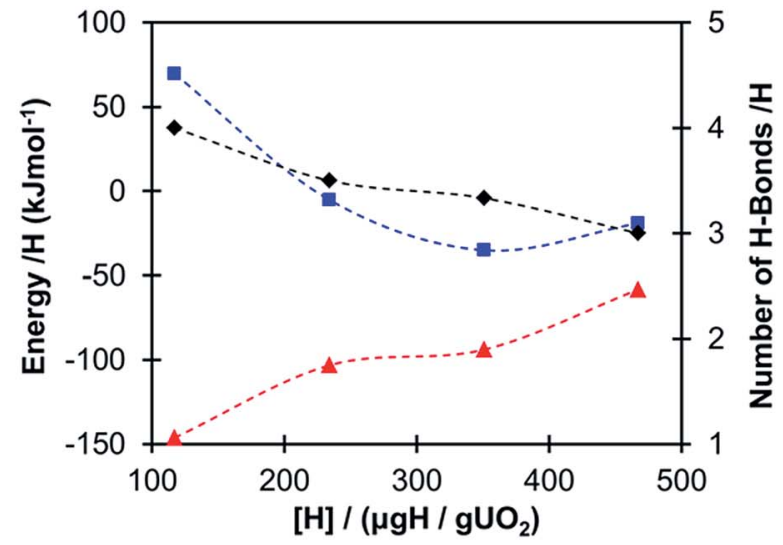

a ${ }^{L} I_{2}^{x}$

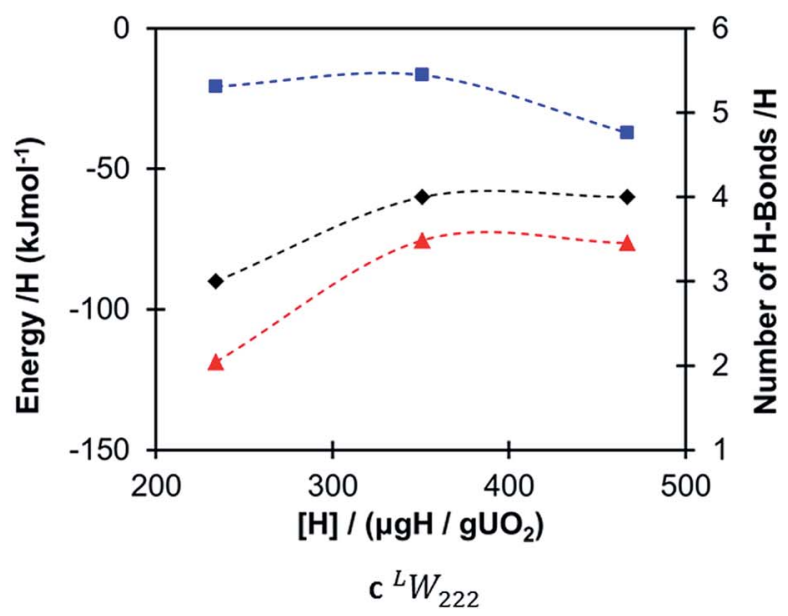

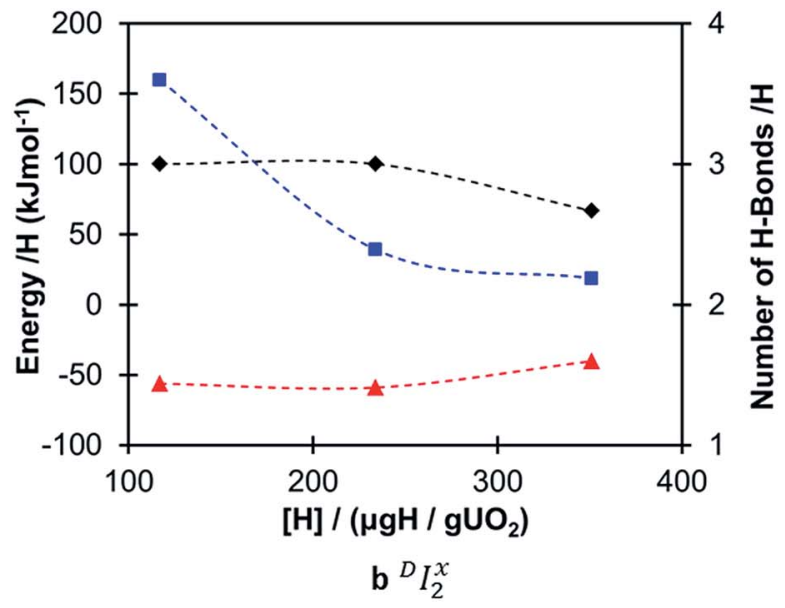

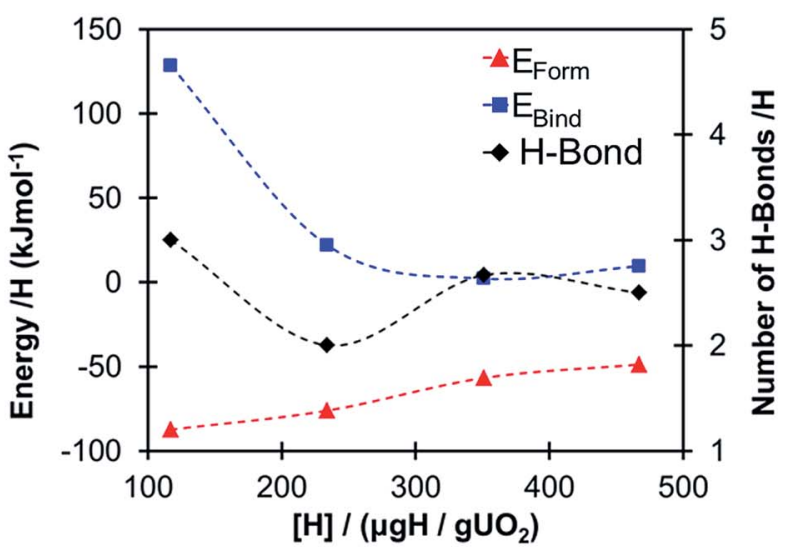

$\mathbf{d}^{D} W_{222}$

Fig. 4 Energetics of oxy-hydroxyl clusters. Formation energy (red triangles) and binding energy (blue squares) per hydrogen, and total number of hydrogen bonds (black diamonds) as a function of local hydrogen concentration for the most stable oxy-hydroxyl defect clusters.

We have investigated hydrogen interaction with two types of oxygen defect cluster (split di-interstitial $\left(I_{2}{ }^{x}\right)$ and $2: 2: 2$ Willis $\left(\mathrm{W}_{222}\right)$ clusters) in uranium oxide. We found that the stability and geometry of these clusters radically change as a function of local hydrogen concentration. These oxygen defect clusters act as hydrogen traps and thus will macroscopically affect the material in terms of mechanical properties and hydrogen solubility and diffusion. This will significantly impact long term storage and disposal of uranium metal as hydrogen diffusion through the protective oxide layer forms pyrophoric hydride at the interfaces.

We found that, remarkably, the presence of hydrogen stabilises the Willis cluster when an appropriate hydrogen bonding network is established, suggesting that trapped hydrogen may have been present when these clusters were originally reported in uranium oxide. ${ }^{20}$ Although the Willis cluster is stabilized by hydrogen, it is only the most stable defect at 234 and $467 \mu \mathrm{g} \mathrm{H} / \mathrm{g} \mathrm{UO}{ }_{2}$, with the split di-interstitial the most stable at 117 and $351 \mu \mathrm{g} \mathrm{H} / \mathrm{g} \mathrm{UO}_{2}$. This indicates that oxygen defect chemistry in $\mathrm{UO}_{2}$ is not only strongly dependent on oxygen stoichiometry, ${ }^{25,26}$ but also on hydrogen partial pressure. This opens key chemical challenges to determine whether other oxy-hydroxyl clusters will be directly stabilised, to what extent these clusters will appear in other materials, and whether the properties of oxide materials will be affected.

For all clusters, with one exception (ESI Table $4 \dagger$ ), addition of hydrogen resulted in the formation of hydroxyl groups, which are essential for the formation of a hydrogen bonding network capable of stabilising oxy-hydroxyl clusters. Although there is little experimental work on the interaction of hydrogen with $\mathrm{UO}_{2}$, hydroxyl groups were suggested as potential traps for hydrogen species by Wheeler ${ }^{17}$ at concentrations of up to $10 \%$. Sherman and Olander ${ }^{19}$ also acknowledged the presence of hydrogen bound to a variety of defects (rather than simply dissolved as interstitial species) and proposed that oxygen vacancies may be a stable location for hydrogen defects. Indeed, our data shows that the Willis cluster can only be stabilized by forming a hydrogen bonding network that prevents an interstitial oxygen $\left(\mathrm{O}^{\prime \prime}\right)$ from moving to the vacant oxygen site (Fig. 1b) and thus relaxing to a $I_{2}{ }^{x}$ cluster. In some of the defect configurations, generally the least stable ones, we observe hydrogen species positioned at oxygen vacancy sites but still bound to an oxygen interstitial, which is in line with the proposition put forward by Sherman and Olander. ${ }^{19}$ 
Based on the formation energies (which define the thermodynamic stability) and binding energies (which define the preference of having oxy-hydroxyl) we can identify, from a thermodynamic viewpoint, reversible and irreversible hydrogen traps in uranium oxide. This provides atom-level parameters that could be implemented in mathematical models to determine hydrogen transport in uranium oxide,,$^{17,19,33,34}$ and each different hydrogen trap now may be considered explicitly. We suggest that oxy-hydroxyl clusters with favourable formation (i.e. negative) and binding energies (i.e. negative) correspond to irreversible traps, as they will form and will not dissociate into isolated defects. Clusters with a favourable formation energy and an unfavourable binding energy $\left(0<E_{\text {Bind }}<80 \mathrm{~kJ} \mathrm{~mol}^{-1}\right)$ represent reversible hydrogen traps. These correspond to metastable intermediates that are reversible in nature, as the clusters can form but they are not the most stable defect configurations however they do not have sufficient energy for the hydroxyl bond to dissociate. ${ }^{35}$ Whereas traps with a binding energy greater than the threshold of $80 \mathrm{~kJ} \mathrm{~mol}^{-1}$ are still metastable intermediates but are less likely to exist, as there is sufficient energy to convert the hydroxyl groups into hydride defects. This threshold for the binding energy of reversible traps (80 $\mathrm{kJ} \mathrm{mol}^{-1}$ ) corresponds to the energy barrier to form an isolated hydride group from a stable isolated hydroxyl species. ${ }^{35}$

Using our definition for the irreversible and reversible nature of hydrogen traps in $\mathrm{UO}_{2}$, we have made an assessment of the probability of these oxy-hydroxyl clusters to be present within the lattice. This helps rationalise the experimentally observed reversible and irreversible hydrogen traps in $\mathrm{UO}_{2}$, by providing atom level insights into the nature of defect clusters within $\mathrm{UO}_{2}$. However, our calculations do not attempt to determine the absolute concentration of traps as this would require the calculation of free energy terms and is beyond the scope of this work, but represents a key area of future development. Furthermore, while the formation and binding energies allow us to define the nature of traps as reversible or irreversible, simply being an irreversible trap does not guarantee a high concentration of that trap. As in order for the cluster to have a greater concentration than the isolated point defects, its binding energy should be lower than the formation energy of the individual components. ${ }^{53}$ Thus, a trap can be irreversible in nature and have a low concentration. Within the cluster configurations studied in this work, the only case where the binding energy is greater than the formation energies of the individual point defects is the ${ }^{L} \mathrm{~W}_{222}^{2 \mathrm{O}^{\prime}, 2 \mathrm{O}^{\prime \prime}}$ cluster (Fig. 3d), which suggests that this might be the dominant irreversible trap for hydrogen in $\mathrm{UO}_{2}$.

We have generated thermodynamic distributions of irreversible and reversible hydrogen traps as a function of temperature, by calculating the probability of different clusters based on their formation energy. Eqn (5) displays the calculation of free energy, where the $\Delta G_{i}$ is the free energy for the oxyhydroxyl cluster $i, \Omega$ is the degeneracy of the oxy-hydroxyl cluster (we report the degeneracy of a cluster in ESI $\dagger$ ), $E_{\mathrm{Form}, i}$ is the formation energy calculated in eqn (2) and we rescale them so that this value to zero for the most stable defect cluster, $R$ is the gas constant and $T$ is the temperature.

$$
\Delta G_{i}=\Omega \mathrm{e}^{\left(\frac{-E_{\mathrm{Form}, i}}{R T}\right)}
$$

The probability is then given by

$$
P=\frac{\Delta G_{i}}{\sum_{i} \Delta G_{i}}
$$

While this approach does not explicitly include the effect of temperature on the defect clusters, as the comparison is between defects all in the solid phase the cohesive energy term will be dominant and entropy terms are unlikely to reverse the conclusions. This again represents key areas for future research, both for the explicit inclusion of temperature and configurational entropy on the stability of defect clusters.

The thermodynamic distribution of all the clusters at each hydrogen concentration is presented in Fig. 5. The calculated probabilities show the predicted nature of the oxy-hydroxyl clusters based on the oxygen defect geometry (i.e. Willis or split di-interstitial) and trap nature (i.e. reversible or irreversible). As the concentration of hydrogen increases, there is a clear shift from reversible trapping, which dominates at the lowest concentration $117 \mu \mathrm{g} \mathrm{H} / \mathrm{g} \mathrm{\textrm {UO } _ { 2 }}$, to irreversible trapping, independent of cluster type (Fig. 5). Although we cannot compare our data directly with experimental de-trapping data, ${ }^{\mathbf{1 7}, \mathbf{1 9}}$ as this accounts for kinetic parameters, it is intriguing that experimental data suggests that hydrogen dissolved in uranium oxide is not released by a diffusion controlled process. Examining the desorption curve for uranium oxide single crystal shows a first desorption peak at approximately $1100 \mathrm{~K}$ and a second and more discernible desorption peak at approximately $1700 \mathrm{~K}$, associated with energies of 80 and $210 \mathrm{~kJ} \mathrm{~mol}^{-1}$ respectively. ${ }^{19}$ This precludes hydrogen diffusion via interstitial sites in the $\mathrm{UO}_{2}$ lattice and supports the idea that hydrogen is bound to discrete sites, as we see in our ab initio model structures. These hydrogen traps will be characterised by a binding energy and a rate constant of release.

While we calculated the binding energies for oxy-hydroxyl defect clusters in uranium oxide, we have no information on the rate constants for hydrogen release, which depend on temperature. When considering a thermodynamic distribution that accounts for all hydrogen traps at all local hydrogen concentrations (Fig. 6), irreversible trapping (i.e. negative binding energy) appears at temperatures higher than $900 \mathrm{~K}$ and is slightly more likely to be based on the Willis geometry $(1.3 \%$ at $1000 \mathrm{~K}$ and $5 \%$ at $2000 \mathrm{~K}$ ) compared to the split di-interstitial $(0.3 \%$ at $1000 \mathrm{~K}$ and $3.5 \%$ at $2000 \mathrm{~K})$. Up to $10 \%$ of irreversible hydrogen traps appear at $2000 \mathrm{~K}$, whereas the majority (up to $90 \%$ ) of hydrogen traps will still metastable intermediates (i.e. reversible traps) based on the $I_{2}{ }^{x}$ cluster (Fig. 6). As the irreversible traps are stabilised by a more complex hydrogen bonding network, they are more stable at higher local hydrogen concentrations and thus their thermodynamic distribution 

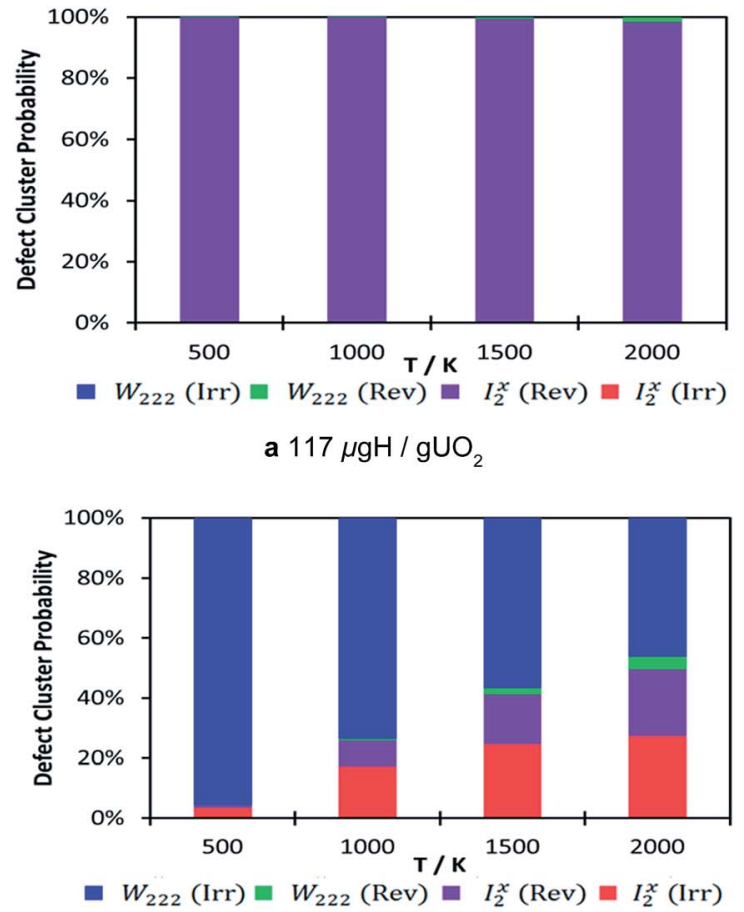

b $234 \mu \mathrm{gH} / \mathrm{gUO}_{2}$

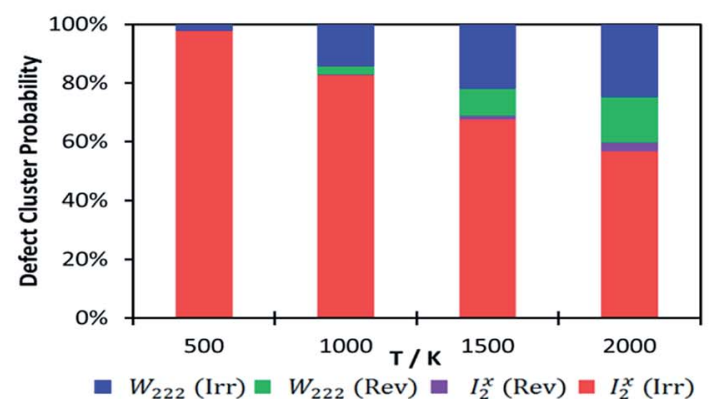

c $351 \mu \mathrm{gH} / \mathrm{gUO}_{2}$

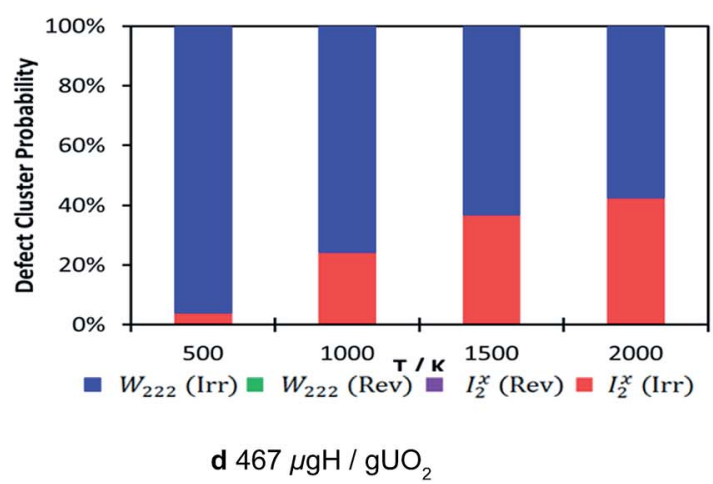

Fig. 5 Defect cluster probability at different local hydrogen concentrations as a function of temperature. The probability has been calculated relative to the most stable cluster for each local hydrogen concentration. Reversible $W_{222}$ shown in green, irreversible $W_{222}$ in blue, reversible $I_{2}{ }^{x}$ purple and irreversible $I_{2}{ }^{x}$ in red.

increases with temperature, contrary to the metastable (reversible) traps that are mainly oxy-hydroxyl clusters with low local hydrogen concentration and a weaker hydrogen bonding network.

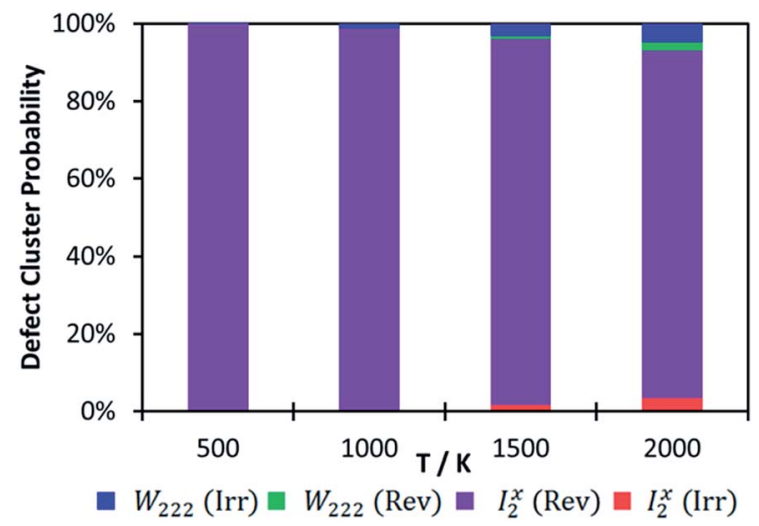

Fig. 6 Defect cluster probability as a function of temperature. The probability has been calculated relative to the most stable cluster for all concentrations. Reversible $W_{222}$ shown in green, irreversible $W_{222}$ in blue, reversible $I_{2}^{x}$ purple and irreversible $I_{2}^{x}$ in red.

\section{Conclusions}

To conclude, we found that hydrogen strongly affects the structure and energetics of oxygen defect clusters in uranium oxide, as has been shown for many other oxides. ${ }^{1-5}$ Our analysis defines a thermodynamic route to determine reversible (metastable) and irreversible hydrogen traps, and show that there are stable local oxygen-rich regions (i.e. oxygen defect clusters) that can trap and sustain high local hydrogen concentrations despite low overall concentration in the sample. Our ab initio approach allows for quantitative measurement of the population of hydrogen traps, which changes as a function of local hydrogen concentration and temperature. This shows that we need atom-level models and insight if we are to predict macroscopic properties such as the dynamics of hydrogen defects and microstructural changes under non-equilibrium conditions that can arise in service due to the presence of extreme environments (e.g. radiation, temperature). Thus this work demonstrates when investigating defect clusters in oxides that the inclusion of hydrogen as part of these studies is overdue.

\section{Conflicts of interest}

There are no conflicts to declare.

\section{Acknowledgements}

The authors thank J. Glascott for useful discussions on hydrogen in actinides. This work made use of ARCHER, the UKs national HPC facility funded by EPSRC (EP/L000202) through the Material Chemistry Consortium, and Balena, the University of Bath HPC platform. We thank AWE, the University of Bath, the University of Huddersfield, and EPSRC (EP/P007821/1, EP/ K016288/1, EP/R010366/1) for funding. () British Crown Owned Copyright 2018/MOD. Published with permission of the controller of Her Britannic Majesty's Stationary Office. 


\section{References}

1 T. Norby, M. Widerøe, R. Glockner and Y. Larring, Dalton Trans., 2004, 3012-3018.

2 T. Norby, Nature, 2001, 410, 877878.

3 T. Norby and Y. Larring, Curr. Opin. Solid State Mater. Sci., 1997, 2, 593-599.

4 S. Ø. Stub, E. Vøllestad and T. Norby, J. Phys. Chem. C, 2017, 121, 12817-12825.

5 L. Meng, X. De-Gang, M. Evan, L. Ju, Z. Xi-Xiang and S. ZhiWei, Nat. Commun., 2016, 8, 14564.

6 C. G. Van de Walle, Phys. Rev. Lett., 2012, 85, 10121015.

7 S. K. Cushing, F. Meng, J. Zhang, B. Ding, C. Chen, L. Ru-Shi, A. D. Bristow, J. Bright, P. Zheng and N. Wu, ACS Catal., 2017, 7, 1742-1748.

8 W. Xin-Ping and G. Xue-Qing, Phys. Rev. Lett., 2016, 116, 086102.

9 H. Malerød-Fjeld, D. Clark, I. Yuste-Tirados, R. Zanon, D. Catalan-Martinez, D. Beeaff, S. H. Morejudo, P. K. Vestre, T. Norby, R. Haugsrud, J. M. Serra and C. Kjølseth, Nat. Energy, 2017, 2, 923-931.

10 E. L. Silva, A. G. Marinopoulos, R. B. L. Vieira, R. C. Valao, H. V. Alberto, J. M. Gil, R. L. Lichti, P. W. Mengyan and B. B. Baker, Phys. Rev. B, 2016, 94, 014104.

11 X. Leng, J. Pereiro, J. Strle, G. Dubuis, A. T. Bollinger, A. Gozer, J. Wu, N. Litombe, C. Pangopoulos and C. I. BoZovi, npj Quantum Materials, 2017, 2, 1-7.

12 A. Borgschulte, O. Sambalova, R. Delmelle, S. Jenatsch, R. Hany and F. Nuesch, Sci. Rep., 2017, 7, 40761.

13 C. A. Colmenares, Prog. Solid State Chem., 1984, 15, 257-364. 14 A. G. Ritchie, J. Less-Common Met., 1984, 98, 193-214.

15 J. M. Haschke, T. H. Allen and L. A. Morales, J. Alloys Compd., 2001, 314, 78-91.

16 C. A. Stitt, N. J. Harker, K. R. Hallam, C. Paraskevoulakpos, A. Banos, S. Rennie, J. Jowset and T. B. Scott, PLoS One, 2015, 10, 1-13.

17 V. J. Wheeler, J. Nucl. Mater., 1971, 40, 189-194.

18 D. R. Olander, D. Sherman and M. Balooch, J. Nucl. Mater., 1982, 107, 31-45.

19 D. F. Sherman and D. R. Olander, Hydrogen dissolution in and release form nonmetals I uranium dioxide, J. Nucl. Mater., 1989, 166, 307-320.

20 B. T. M. Willis, Nature, 1963, 197, 755-756.

21 C. R. A. Catlow, Proc. R. Soc. London, 1977, 353, 533-561.

22 D. A. Andersson, J. Lezama, B. P. Uberuaga, C. Deo and S. D. Conradson, Phys. Rev. B, 2009, 79, 024110.

23 H. Geng, Y. Chen, Y. Kaneta, M. Iwasawa, T. Ohnuma and M. Kinoshita, Phys. Rev. B: Condens. Matter Mater. Phys., 2008, 77, 104120.

24 J. Wang, R. C. Ewing and U. Becker, Sci. Rep., 2014, 4, 4216. 25 N. A. Brincat, M. Molinari, S. C. Parker, G. C. Allen and M. T. Storr, J. Nucl. Mater., 2015, 456, 329-333.

26 N. A. Brincat, M. Molinari, G. C. Allen, M. T. Storr and S. C. Parker, J. Nucl. Mater., 2015, 467, 724-729.
27 F. Gupta, G. Brillant and A. Pasturel, Philos. Mag., 2007, 87, 2561-2569.

28 L. Desgranges, G. Baldinozzi, D. Simeone and H. E. Fischer, Inorg. Chem., 2016, 55, 7485-7491.

29 B. Dorado, G. Jomard, M. Freyss and M. Bertolus, Phys. Rev. B: Condens. Matter Mater. Phys., 2010, 82, 035114.

30 S. T. Murphy, E. E. Jay and R. W. Grimes, J. Nucl. Mater., 2014, 447, 143-149.

31 N. R. Williams, M. Molinari, S. C. Parker and M. T. Storr, J. Nucl. Mater., 2015, 458, 45-55.

32 L. Sun, D. Marrocchelli and B. Yildiz, Nat. Commun., 2015, 6, 6294.

33 J. Glascott, Philos. Mag., 2014, 94, 221-241.

34 J. Glascott, Philos. Mag., 2014, 94, 1393-1413.

35 J. M. Flitcroft, N. A. Brincat, M. Molinari, S. C. Parker and M. T. Storr, Chem. Commun., 2015, 51, 16209.

36 A. Bingyun, Q. Ruizhi, L. Haiyan and C. Piheng, J. Phys. Chem. C, 2016, 120, 18445-18451.

37 T. Bo, J. Lan, Y. Zhao, C. He, Z. Chai and W. Shi, J. Nucl. Mater., 2014, 54, 446-454.

38 B. E. Tegner, M. Molinari, A. Kerridge, S. C. Parker and N. Kaltsoyannis, J. Phys. Chem. C, 2016, 121, 1675-1682.

39 G. Kresse and J. Furthmuller, Phys. Rev. B: Condens. Matter Mater. Phys., 1996, 54, 11169-11186.

40 J. P. Perdew, K. Burke and M. Ernzerhof, Phys. Rev. Lett., 1996, 77, 3865-3868.

41 M. R. Castell, S. L. Dudarev, C. Muggelberg, A. P. Sutton, G. A. A. D. Briggs and D. T. Goddard, J. Vac. Sci. Technol., 1998, 16, 1055.

42 T. Yamazaki and A. Kotani, J. Phys. Soc. Jpn., 1991, 60, 49-52. 43 N. A. Brincat, S. C. Parker, M. Molinari, G. C. Allen and M. T. Storr, Inorg. Chem., 2014, 53, 12253-12264.

44 R. Laskowski, G. K. H. Madsen, P. Blaha and K. Schwarz, Phys. Rev. B: Condens. Matter Mater. Phys., 2004, 69, 140408.

45 L. Kleinman, Phys. Rev. B: Condens. Matter Mater. Phys., 1980, 21, 2631.

46 A. H. MacDonald, W. E. Pickett and D. D. Koelling, J. Phys. Chem. C, 1980, 13, 2675-2683.

47 F. Bottin, G. Geneste and G. Jomard, Phys. Rev. B: Condens. Matter Mater. Phys., 2016, 93, 115438.

48 P. Santini, R. Lemanski and P. Edros, Adv. Phys., 1999, 48, 537-653.

49 X. D. Wen, R. L. Martin, L. E. Roy, G. E. Scuseria, S. P. Rudin, E. R. Batista, T. M. McCleskey, B. L. Scott, B. Bauer, J. J. Joyce and T. Durakiewicz, J. Chem. Phys., 2012, 137, 154707.

50 G. W. Watson, E. T. Kelsey, N. H. deLeeuw, D. J. Harris and S. C. Parker, J. Chem. Soc., Faraday Trans., 1996, 92, 433-438.

51 K. Momma and F. Izumi, J. Appl. Crystallogr., 2008, 41, 653658.

52 L. Minervini, M. O. Zacate and R. W. Frimes, Solid State Ionics, 1999, 116, 339-349.

53 C. G. Van de Walle and J. Neugebauer, J. Appl. Phys., 2004, 91, 3851-3879. 